\title{
REFLEXIONES EN TORNO AL CURRÍCULO EN LA UNIVERSIDAD
}

\author{
REFLECTIONS AROUND THE CURRICULUM IN THE UNIVERSITY \\ Manuel Miluánovich Castilla ${ }^{1}$ \\ Universidad Nacional Mayor de San Marcos, Lima, Perú \\ (RECiBido el 06/05/2010, ACEPTAdo el 19/07/2010)
}

\section{INTRODUCCIÓN}

El tema del currículo en la universidad ocupa un lugar central y de creciente importancia en la discusión acerca de las relaciones entre la educación y el desarrollo.

Diversos enfoques y planteamientos intentan dilucidar tópicos trascendentales como la concreción de los fines de la educación en los escenarios de hoy, enmarcados por la globalización, el poder del conocimiento y la búsqueda, a veces angustiosa, de medios que favorezcan la internalización auténtica de valores elevados, de sentido moral, ético-social y cognoscitivo, expresables individual y colectivamente.

\section{El proceso en San Marcos y otras universidades}

El interés y la preocupación por el tema del currículo en el ámbito sanmarquino son de vieja data, aunque con mucha heterogeneidad según las facultades, tanto en el nivel teórico como en el de sus aplicaciones. Su evolución presenta, a grandes rasgos, las características que a continuación reseñamos.

\section{a) Modernización de los aspectos pedagógicos de la educación universitaria}

Durante mucho tiempo prevaleció la convicción de que en la enseñanza universitaria lo único importante era la preparación especializada del catedrático y su solvencia académica, mientras que las cuestiones didácticas y metodológicas solo eran relevantes en la educación inicial, primaria y secundaria.

Hace algunas décadas se empezó a otorgar creciente importancia a la didáctica de la educación universitaria, sobre la base de modelos vigentes en países de Europa y Norteamérica, a tono con los acelerados cambios teóricos, tecnológicos e ideológicos que venían ocurriendo en el campo de la educación y en las ciencias conexas.

1 Docente principal de la Facultad de Psicología de la UNMSM. 


\section{b) Creciente sensibilización}

Creciente sensibilización frente a las nuevas demandas que el desarrollo del país y la sociedad, en general, plantean a la educación de hoy y de mañana, bajo la premisa de que esta constituye la principal palanca impulsora de los cambios hacia un modelo de desarrollo integral, equitativo y autosostenido.

Marco general de referencias definido por el paradigma de la sociedad del conocimiento y por la globalización, como escenario de aquella.

\section{c) Requerimientos de modernización}

Requerimientos de modernización de las universidades, con énfasis en la autoevaluación institucional y la acreditación, como medios para la optimización de la formación profesional, la investigación y la proyección social.

\section{d) Influencia de la psicología cognitiva}

Influencia dominante de la psicología cognitiva como el principal fundamento de los sistemas educativos modernos, en concordancia con el desplazamiento del enfoque conductista, después de un largo periodo de preeminencia excluyente.

\section{e) Políticas de gobierno y de gestión universitaria}

Orientadas, con diversos matices, a elevar la calidad de los aprendizajes y el logro de competencias en función de los perfiles profesionales, bajo el supuesto de que estos son diseñados y progresivamente reajustados como respuesta a la dinámica de los cambios sociales, económicos y políticos del entorno.

\section{Las demandas educativas de la sociedad moderna}

Los sistemas educativos modernos pugnan por responder cabalmente a las demandas cada vez más complejas de las sociedades actuales y del futuro, en un mundo caracterizado por la globalización, los acelerados avances de la informática y el rol determinante del conocimiento, cuyo caudal se incrementa vertiginosamente como resultado de la investigación científica, humanística y tecnológica, realizada principalmente en las universidades.

En este contexto, es imperativo que la universidad encare su propia transformación para elevar progresiva y continuamente la eficacia de su contribución al desarrollo del país, con libertad, justicia, equidad y solidaridad, y con arreglo al ineluctable paradigma basado en el poder del conocimiento y el manejo adecuado de la información.

\section{Aportes de la universidad}

Una de las metas de la universidad, en armonía con lo anterior, es la formación de personal altamente especializado, y a la vez culto y dotado de sensibilidad y elevada racionalidad; así como imbuido del imperativo de la educación permanente y equipado con herramientas mentales para el logro de aprendizajes cada vez más complejos, especialmente en el nivel metacognitivo. 
La capacidad de aprendizaje en este contexto debe entenderse, a la luz de las teorías psicológicas cognitivas que sustentan los sistemas educativos modernos, como capacidad de aprendizaje de alta calidad, lo cual excluye categóricamente la tendencia a los aprendizajes memorísticos por ser estos estériles e inútiles y privilegian, más bien, los aprendizajes que reúnen las cualidades de pertinencia, significatividad, transferencialidad, reflexividad y recuperabilidad, así como la propiedad de operar crecientemente en el nivel metacognotivo y la de tener un valor instrumental, recurrentemente enriquecido para que la persona siga aprendiendo permanentemente en la perspectiva de su realización personal y de su aporte social.

\section{Paradigmas y propuestas teóricas acerca del currículo}

Desde el punto de vista de los modelos aplicativos derivados de las teorías cognitivas en referencia, entre los cuales destaca la hipótesis del aprendizaje significativo de D. Ausubel, y desde el ángulo de los conceptos pedagógicos modernos, la calidad de los aprendizajes académicos depende fundamentalmente de los ensayos de procesamiento que el estudiante efectúa con la información adquirida por la vía de la observación, la interacción con el docente, de la lectura, de la experimentación, la reflexión, etc.

Tal procesamiento consiste básicamente en una elaboración conceptual de creciente complejidad, no exenta de errores y enmiendas recurrentes, que se orienta a la organización de los contenidos y a su engarce con los conocimientos previos del sujeto y con su estructura cognoscitiva, en general.

Martiniano Román Pérez (2004) sostiene que la sociedad del conocimiento exige a la escuela y a la universidad una relectura de su estructura y funciones desde el nuevo paradigma por él denominado sociocognitivo y humanista, teniendo en cuenta, por otro lado, que el paradigma conductista y positivista, propio de la sociedad industrial, está agotado.

Asimismo, Román Pérez considera que el concepto hoy tan apreciado de aprender a aprender es confuso y equivoco si no lo centramos en el cultivo de la inteligencia afectiva (recusa la frase inteligencia emocional) que permite integrar adecuadamente capacidades y valores, así como posibilitar su desarrollo mediante la aplicación de estrategias de aprendizaje cognitivas y metacognitivas, y mediante la promoción de modelos mentales avanzados (desarrollo de la arquitectura mental).

Todo ello facilita, a su vez, la modificabilidad estructural cognitiva y afectiva en base al siguiente supuesto: los contenidos (formas de saber) y los métodos (formas de hacer) son medios para desarrollar capacidades (a partir de destrezas y habilidades) y valores (a partir de actitudes).

Nosotros planteamos que la aludida reestructuración cognitiva y afectiva encuentra un sólido fundamento científico en el pensamiento, abundantemente documentado, de Reuven Feuerstein sobre reestructuración cognitiva.

\section{La pluralidad conceptual alrededor de currículo}

Se puede sostener que hay dos clases de propuestas acerca de la extensión del concepto de currículo, a saber: 
a) Una concepción restrictiva del currículo, en el sentido de que este término alude solo a las preguntas cardinales respecto al proceso enseñanza-aprendizaje: "a quiénes", "para qué”, "por qué”, "cómo”, “dónde”, "cuándo”, enseñar-aprender. Todas estas preguntas son de carácter pedagógico.

b) Una concepción extensiva del currículo, que incluye sus fundamentos, fuentes de influencia y dinámica interactiva, según la cual el currículo no solo responde a las demandas del entorno, sino que es capaz de modularlas y corregirlas, así como de crear nuevas necesidades constructivas y enriquecedoras.

Además, el modelo extensivo de currículo incluye guías didácticas y otros instrumentos que contribuyen a plasmar exitosamente la ejecución curricular.

El currículo, en esta perspectiva, parte de una concepción del hombre, de la vida y del mundo e interactúa con diversas fuentes: filosófica, pedagógica, psicológica, antropológica, sociológica, económica, política, informática, etc. La interacción consiste básicamente en que el currículo recibe las influencias de las referidas fuentes y sus respuestas influyen, a su vez, en la dinámica de aquellas.

Una definición de currículo, coherente con este marco conceptual, es la siguiente: el currículo es un conjunto sistemático de previsiones para llevar a cabo la acción educativa que responde a las siguientes preguntas, referidas al proceso enseñanza-aprendizaje: qué enseñar-aprender, a quién o a quiénes, para qué, cuándo, dónde, cómo, quiénes, con qué recursos, con arreglo a qué marco normativo de política educacional, qué evaluar, con qué recursos técnicos, quiénes ejercen la función evaluadora, para qué, cuándo y dónde.

Esta propuesta enfatiza la concepción del hombre en general y los rasgos del hombre y la mujer ciudadanos, libres y solidarios, en quienes se compatibilizan la realización personal y el aporte al desarrollo del país y de la sociedad. Otro de los fundamentos son los perfiles de las carreras que ofrecen las universidades, expresados en términos de competencias, sobre la base de un modelo estándar de conceptualización y operativización de lo que se entiende por "competencia".

Por otro lado, sin pretender inmiscuirse en los campos de la administración educacional, el currículo debe incluir algunas consideraciones generales sobre dicha materia, sin las cuales el currículo podría quedar confinado a un plano abstracto y desvinculado de las previsiones de su implementación.

A continuación consignamos extractos del pensamiento de reconocidos tratadistas en el campo temático del currículo. Walter Peñaloza Ramella, autor de libros y artículos sobre la materia, sostiene que el currículo tiene carácter eminentemente teleológico, esto es, persigue fines, de los cuales se derivan objetivos de diversos niveles. "Si el currículo tiene carácter teleológico frente a la noción de lo que es educación, ello quiere decir - expresado en otros términos - que aquella noción de educación es el fin y que el currículo es el medio para arribar a ese fin. En toda relación teleológica hay siempre un medio y un fin" (Peñaloza, 1995).

José María Ruíz Ruíz (2005) cita los conceptos del currículo de calificados especialistas como Stenhouse, 1981; Dieuzeude, 1981; Pinar, 1983; Zabalza, 1984; Coll, 1987; Gimeno, 1988 y Fernández Pérez, 1994, y Román Pérez, 1994. 
El mismo autor, José María Ruíz Ruíz (2007) incorpora al tema del currículo la propuesta de la Comisión Internacional para la Educación en el siglo XXI mediante el epítome: "enseñar a conocer, a hacer, a vivir juntos, y a ser".

Zabalza (1987) concibe el currículo en base a los supuestos de partida, de las metas que se desean lograr y los pasos que se darán para alcanzarlas: el conjunto de conocimientos, habilidades y actitudes que se consideran importantes trabajar en la escuela año tras año. Gimeno (1988) afirma que el currículo es el eslabón entre la cultura y la sociedad exterior a la escuela y la educación; entre el conocimiento o cultura heredados y el aprendizaje de los alumnos; entre la teoría y la práctica posible, dadas unas determinadas condiciones.

Coll (1987) entiende por currículo el proyecto que preside las actividades educativas escolares, precisa sus intenciones y proporciona guías de acción adecuadas y útiles para los profesores que tienen la responsabilidad directa de su ejecución.

\section{El concepto de competencia}

Lo primero que se constata al revisar la literatura sobre este tema es que se trata de un término polisémico y que su empleo más allá del auxilio del contexto es redundante y algo anárquico. Los intentos por definir las competencias como capacidades, habilidades, destrezas o aptitudes no resuelven el problema por cuanto se cae en la circularidad de las definiciones lexicográficas, contrastables con diccionarios autorizados, vale decir, las capacidades se definen como habilidades, y las habilidades como capacidades, y estas como aptitudes o destrezas, de modo que se puede cubrir la matriz combinatoria de posibilidades lógicas sin que se haya dilucidado nada y entonces campea la vaguedad y ambigüedad.

Adquiere, pues, importancia decisiva el contexto y la correspondiente definición de términos, una alternativa viable de esclarecimiento consiste en examinar los trasfondos de las competencias como sus elementos fundamentales, teóricos de conceptos empleados en materia de teorías y técnicas curriculares, y de que se concretizan en currículos concebidos, diseñados, elaborados, programados, ejecutados, evaluados y reajustados dentro de procesos recurrentes en espiral ascendente acompañados constantemente de ecuánime reflexión por parte de sus agentes y usuarios, lo cual permitiría avanzar sin pretender resolver concluyentemente el problema. En tal sentido se ha avanzado, invocando el pensamiento de Robert Gagné y autores posteriores, en términos de los componentes de las competencias, entendidas estas como "saberes" o conocimientos según la siguiente taxonomía:

a) Saber qué (saber declarativo): son los conocimientos conceptuales que tienen como fundamento alguna teoría o conjunto de teorías.

b) Saber cómo (saber procedimental): son las acciones que se deben realizar para el logro de un objetivo. No se trata del conocimiento de prescripciones o de reglas técnicas para hacer algo sino de la capacidad real, actual, en términos aristotélicos, que posee una persona, como producto de su entrenamiento o práctica razonada.

c) Dimensión afectiva: principalmente las actitudes, desde el ángulo de sus componentes y de su valencia.

d) Saber categorial: los esquemas mentales que posibilitan la clasificación, el discernimiento de niveles de generalidad y la organización del conocimiento. 
La aplicación del enfoque en mención hace posible el manejo discriminativo y coherente de las competencias en los temas curriculares y en el de los perfiles profesionales. Consignamos a continuación, como ejemplo, el listado de las competencias genéricas en la taxonomía de Tuning, relacionada con el desarrollo personal y la formación ciudadana, citadas por el Dr. José María Ruíz Ruíz.

Ejemplo de competencias básicas, genéricas y especificaciones en la formación de la carrera docente (Ruíz Ruíz, J. M., 2005).

- Capacidad de análisis y síntesis.

- Toma de decisiones.

- Capacidad de aplicar conocimientos en la práctica.

- Trabajo en equipo.

- Planificación y gestión del tiempo.

- Conocimientos generales básicos sobre el área de estudio.

- Conocimientos de idiomas.

- Habilidades interpersonales.

- Capacidad para interpretar.

- Liderazgo.

\section{Innovaciones respecto al sílabo}

El tema del currículo, cuando además de lo teórico es abordado operacionalmente, nos pone frente al sílabo como pieza fundamental de concreción y coherencia de aquel.

Descontada, por obvia, la necesidad de que el sílabo sea formulado en términos de competencias, genéricas y específicas, la sumilla de la asignatura juega un papel preponderante, por cuanto debe sintetizar los objetivos, los contenidos, los procesos cognoscitivos involucrados, así como breves referencias a la metodología didáctica y a la evaluación.

El sentido y la utilidad de las sumillas bien formuladas se hacen patentes cuando se constata que ellas son elementos indispensables de los sílabos de las asignaturas incluidas en el currículo de cada carrera. Las sumillas no son formuladas por el profesor y constituyen una pieza infaltable de los sílabos porque garantizan el mantenimiento del contenido básico y la intencionalidad de las asignaturas, como parte de un conjunto sistemático mayor, como es el plan curricular de una determinada carrera, mientras este se mantenga vigente.

Las sumillas adecuadamente formuladas garantizan que, independientemente de quien dicte la asignatura, la intencionalidad y el contenido del curso se mantendrá, con el solo margen de variabilidad que otorga la libertad de cátedra, en cuanto a estilo y énfasis, conforme a la tradición y las normas fundamentales de la institución universitaria. 
En armonía con lo anterior, las sumillas deben tener la siguiente estructura:

a) Denominación de la asignatura o curso.

b) Carácter del curso: teórico, práctico o teórico-práctico. A cargo de un solo profesor o colegiado.

c) Objetivo general del curso.

d) Síntesis del contenido temático en términos de competencias.

e) Breve referencia a la metodología didáctica.

f) Breve referencia a la evaluación.

Las ventajas del manejo de las sumillas en los términos señalados se hacen patentes en los procesos de evaluación y reajustes curriculares.

\section{REFERENCIAS BIBLIOGRÁFICAS}

1. Roman Perez, M. (2004). Sociedad del conocimiento y refundación de la escuela desde el aula. Madrid: Facultad de Educación de la Universidad Complutense de Madrid.

2. Gagne, Robert (1997). En Diaz Barriga, Angel, Didáctica y curriculum, Buenos Aires: Convergencia.

3. Richelle, M. y Feuerstein, Reuven (1957). Enfants juifs nord-africans. Jerusalem: Youth Alyah.

4. Peñaloza, Walter (2000). Teoría del curriculum. Lima: Facultad de Educación U.N.M.S.M.

5. Ruiz R., Jose Maria (2005). Diseño de estrategias metodológicas en la ACI según los ECTS. Madrid: Grupo Editorial Universitario. 